\title{
O DESASSOSSEGO DA MODERNIDADE
}

\author{
Camilo Mattar Raabe ${ }^{1}$
}

RESUMO: O estudo tem como foco a questão identidade e alteridade no Livro do desassossego, de Fernando Pessoa, buscando precisar a importância do binômio no Modernismo e na obra em pauta. Fernando Pessoa é um dos poetas que mais questionou a identidade do sujeito moderno, sendo a poética dos heterônimos deveras ilustrativa da fragmentação da personalidade em meio aos avanços tecnológicos e culturais que tiveram início em meados do século XIX. Primeiramente, será definido o conceito de identidade e alteridade, considerando as ideias que o Modernismo herdou do Simbolismo, para, a seguir, analisar a questão do binômio identidade e alteridade, propriamente, no Livro do desassossego, considerando os diversos aspectos do binômio figurados na obra.

PALAVRAS-CHAVE: Identidade e alteridade; Livro do desassossego; Fernando Pessoa.

\section{THE DISQUIET OF MODERNITY}

ABSTRACT: The focus of the study is the binomial identity and alterity in Fernando Pessoa's Livro do desassossego, aiming to elucidate the importance of the binomial for the Modernism and to the mentioned book. The question of identity and alterity is important to understand the criticism of the Modernism into a society in crisis, being Pessoa one of the poets that more worked with the idea of the fragmentary personality of the modern subject. Thirst will be defined the concept of identity and alterity, considering some ideas the Modernism herded from the XIX century, present in the Symbolism; second will be analyzed the characteristics of the binomial identity and alterity in Livro do desassossego, considering the many levels it appears.

KEYWORDS: Identity and alterity; Livro do desassossego; Fernando Pessoa.

${ }^{1}$ Mestrando do curso de Teoria da Literatura da PUCRS. 
A enciclopédia Larousse Cultural apresenta o significado de alteridade como "Estado, qualidade daquilo que é outro, distinto (antônimo de Identidade)". Ao focar seu significado na filosofia e psicologia, considera, sobre a primeira, "a relação de oposição entre o sujeito pensante (o eu) e o objeto pensado (o não eu)" e, sobre a segunda, às "relações com outrem". (1999, p. 220).

Todorov desenvolve a relação entre eu e outro em "A conquista da América: a questão do outro", considerando que "Pode-se descobrir os outros em si mesmo, e perceber que não se é uma substância homogênea e radicalmente diferente de tudo o que não é si-mesmo; eu é um outro." Seguindo, "Posso conceber os outros como uma abstração, como uma instância da configuração psíquica de todo indivíduo, como o Outro, outro ou outrem em relação a mim.” (TODOROV, 1988, p. 3).

Para o Modernismo, o binômio identidade e alteridade é de grande importância, no entanto, tem algumas peculiaridades. Para abordar tal conceito é necessário ter em foco o contexto no qual as primeiras tendências da lírica moderna surgiram, a fim de compreender a crise ontológica que levou à fragmentação - que redunda na heteronímia pessoana - própria ao Modernismo português. "Toda a vida da alma humana é um movimento na penumbra. Vivemos num lusco-fusco da consciência, nunca certos com o que somos ou com o que nos supomos ser." (PESSOA, 2006, p. 94).

O Modernismo representa o momento culminante do dissídio entre a modernidade tecnocientífica e a modernidade cultural. Ao longo do século XIX é possível rastrear nas sucessivas gerações de escritores e artistas um crescente rancor contra o ethos da modernidade, a um só tempo, dessacralizador e massificador. Com tais mudanças sociais surge uma vanguarda que reivindicará para a obra de arte uma posição autônoma face às antinomias do mercado, vanguarda esta que acaba por formular uma crítica da função da arte mediante a crítica dos discursos representacionais que a sustentavam e que, até então, não tinham sido questionados. (BIBLOS, 2001, p. 842).

Como crítica ao processo de modernização, denunciando a aguda crise do sujeito, existe uma série de temas próprios ao Modernismo. Primeiramente, a euforia do moderno que, muitas vezes, desliza rapidamente para o tédio, situado num dos estágios finais de um crescente que pode chegar a desembocar na dissolução do sujeito e no suicídio; o que vem a 
ser um desenlace patético do esforço de autoconhecimento, desenvolvido (muitas vezes de forma obscura, interiorizada e desligada do social) por este homem que acaba por representar a personagem do Modernismo. Certos elementos temáticos são projetados em tópicos como a máscara, o retrato, o espelho e a procura labiríntica do outro em si mesmo. (Cf. REIS, 2003, p. 465).

O Modernismo não apresenta um herói romântico, mas, ao contrário, como crítica à dissolução de valores operada pela modernidade e às demais consequências que este momento proporciona, adota uma atitude definitivamente antirromântica, nos mostrando a fragmentação da identidade, a descontinuidade ontológica que não permite a ilusão do eu unitário do romantismo. "A personagem individual e imponente, que os românticos figuravam em si mesmos, várias vezes, em sonho, a tentei viver, e, tantas vezes quantas a tentei viver, me encontrei a rir alto da minha ideia de vivê-la. (...) Levo comigo a consciência da derrota como um pendão de vitória." (PESSOA, 2006, p. 83-85).

"É sabido como, em Fernando Pessoa, a crise do sujeito e o processo de autognose envolvem uma fragmentação heteronímica.” (REIS, 2003, p. 466). Essa fragmentação heteronímica reflete a autonomia da arte e o distanciamento do eu lírico do eu empírico, que tem suas primeiras manifestações em Baudelaire, Rimbaud e Mallarmé, influenciando as posteriores gerações, como consta no ensaio de T. S. Elliot, "Tradition and the individual talent", 1920: "The emotion of art is impersonal. And the poet cannot reach this impersonality without surrendering himself wholly to the work to be done.” (parte III).

Rimbaud, em carta a Paul Demeny datada de 15 de maio de 1871, escreve: “Pois 'eu' é outro. (...) Assisto ao desabrochar de meu pensamento, eu o vejo, eu o escuto. (...) É falso dizer: penso. Dever-se-ia dizer: pensa-se em mim.” (Apud FRIEDRICH, 1978, p. 62). Aqui encontramos a dissolução do sujeito empírico, em que o conceito de alteridade e identidade se mesclam. Para Hugo Friedrich, que aponta o começo da lírica moderna com Baudelaire, Rimbaud e Mallarmé, o “eu que fala nas poesias de Rimbaud não pode ser concebido a partir da pessoa do autor, assim como o eu de Les Fleurs du Mal." (FRIEDRICH, 1978, p. 69). Questões biográficas podem contribuir para muitas explicações psicológicas dos textos de tais escritores, mas pouco servem para chegar conhecimento do "eu poético". "Este eu pode vestir todas as máscaras, estender-se a todas as formas de existência, a todos os tempos e povos. (...) 
Com Rimbaud, começou aquela separação anormal entre o sujeito poético e o eu empírico (...).” (FRIEDRICH, 1978, p. 69).

Um aspecto que deve ser salientado para a compreensão do binômio identidade e alteridade é a questão do flanêur e sua relação com a multidão que emerge nas ruas de Paris do século XIX, em especial nas galerias, caminhos cobertos de vidro que delimitavam os grandes estabelecimentos comerciais, onde se concentrava a efervescência do moderno e seus bens de consumo. "Os flâneurs eram os indivíduos errantes pelas ruas parisienses, principalmente pelas galerias (...), chamados de botânicos do asfalto, observadores que encontravam o seu incógnito em uma análise alheia.” (BENJAMIN, 1989, p. 47).

"O poeta goza o inigualável privilégio de poder ser, conforme queira, ele mesmo ou qualquer outro. Como almas errantes que buscam um corpo, penetra, quando lhe apraz, a personagem de qualquer um. Para o poeta, tudo está aberto e disponível; se alguns espaços lhe parecem fechados, é porque aos seus olhos não valem a pena serem inspecionados." (Baudelaire, em $A s$ Multidões, Apud BENJAMIM, 1989 p. 55).

A relação entre eu e outro apontada por Baudelaire envolve um complexo paradoxo: encontrar o seu próprio incógnito mediante uma análise do outro. O outro, dessa forma, se funde ao eu, uma vez que é uma projeção do próprio eu que se descobre a si mesmo no outro. "O flâneur é um abandonado na multidão" (BENJAMIN, 1989, p. 51), um estrangeiro em meio a tais mudanças sociais, busca rechaçar a realidade visando a uma transcendência da mesma. "Sou um homem para quem o mundo exterior é uma realidade interior. Sinto isso não metafisicamente, mas com os sentidos usuais com que colhemos a realidade." (PESSOA, 2006, p. 427).

Pra Friedrich, o "desconcertante de tal modernidade é que está atormentada até à neurose pelo impulso de fugir do real, mas se sente impotente para crer ou criar uma transcendência de conteúdo definido, dotada de sentido." (FRIEDRICH, 1978, p. 49). É nessa relação entre o tédio e a dissolução do eu, do spleen e o ideal, em que o poeta busca a fuga de tal realidade rumo ao desconhecido. Rimbaud falava sobre "escrutar o invisível, ouvir o inaudível” (apud FRIEDRICH, 1978, p. 62), mas essa transcendência é sempre imperfeita e negativa: “A idealidade vazia, o 'outro' indefinido que, no caso de Rimbaud é mais indefinido ainda e no de Mallarmé se converterá no Nada, e o mistério que gira em torno de si mesmo, próprio da lírica moderna, são correspondentes.” (FRIEDRICH, 1978, p. 49). 
Nessa busca pelo desconhecido o sujeito sofre a dissolução de sua personalidade real. Essa transcendência nunca se completa, motivo pelo qual a denominação de tal desconhecido encerra características negativas: o nada, o outro indefinido, o vazio. Aqui encontramos aspectos próximos da dissolução do eu e do suicídio, temas presentes na literatura moderna, como resultado da tentativa de autoconhecimento. As palavras nada, outro e vazio, entre outras com ideias semelhantes, são recorrentes em o Livro do desassossego, ilustrando a impossibilidade do sujeito moderno de transcender a realidade no qual inserido. "Nós nunca nos realizamos. Somos dois abismos - um poço fitando o céu.” (PESSOA, 2006, p. 50).

Para encerrarmos a análise das manifestações que influenciaram o distanciamento do sujeito poético do empírico e a impessoalidade da arte moderna, consideremos a famosa carta que Mallarmé, em maio de 1867, escreve para Cazalis: "Sou agora impessoal, não sou o Stéphane que conhecestes mas sim uma capacidade do universo espiritual de ver-se e de desenvolver-se a si mesmo e, precisamente, através do que foi meu eu. Só me cabe aceitar os desenvolvimentos absolutamente necessários, para que o universo encontre neste eu sua identidade." (Apud FRIEDRICH, 1978, p. 126). A formulação, para Friedrich, é um pouco descuidada; todavia seu sentido deveria ser claro: em lugar do eu empírico sucede um eu impessoal, que é a sede onde o universo realiza sua identificação espiritual.

"Se penso, é porque divago; se sonho, é porque estou desperto. Tudo em mim se embrulha comigo, e não tem forma de saber de ser." (PESSOA, 2006, p. 423). Fernando Pessoa alcança o extremo da fragmentação de sua personalidade, numa complexa relação que mescla a identidade e a alteridade. A dissolução de seu eu empírico tem como consequência a impessoalidade, elemento que possibilita o artista encerrar os outros dentro de si mesmo, eis a pluralidade do ego refletindo a fragmentação da modernidade.

Uma vez considerados aspectos ilustrativos da relação identidade e alteridade, notamos que a noção ampla que essa relação abarca. No Livro do desassossego, tal relação pode ser focada em distintos aspectos. Primeiramente, a relação de Fernando Pessoa com Bernardo Soares, seu semi-heterônimo, comentada em cartas do poeta e no diálogo entre ortônimo e semiheterônimo, presente no prefácio da obra; depois, a relação de Bernardo Soares com os outros, e por último, a consequência da dissolução do sujeito, transcendendo ao nada, ao vazio, ao outro indefinido. 
Um dos elementos que caracteriza Fernando Pessoa - mas também presente em demais poetas do Modernismo - é a questão da heteronímia. O escritor representou a fragmentação de sua identidade de modo a criar diversos heterônimos em mútua relação. A poética dos heterônimos - que confere capacidade discursiva autônoma para cada um dos mesmos - só é possível através do distanciamento do eu empírico, numa espécie de fingimento poético próprio ao Modernismo.

Em carta a Adolfo Casais Monteiro, em 13 de janeiro de $1935^{2}$, Pessoa explica a origem dos heterônimos, relatando que os mesmos surgem do "fundo traço de histeria que existe em mim. Não sei se sou simplesmente histérico, se sou, mais propriamente, um histeroneurasténico.” Em outras palavras, “a origem mental dos meus heterónimos está na minha tendência orgânica e constante para a despersonalização e para a simulação.” Pessoa fora diagnosticado como esquizoide - fator que provavelmente se relaciona com a complexidade de sua poética dos heterônimos. Tal tendência, de fato, já era manifesta desde criança, ao "criar em meu torno um mundo fictício, de me cercar de amigos e conhecidos que nunca existiram. (Não sei, bem entendido, se realmente não existiram, ou se sou eu que não existo. Nestas coisas, como em todas, não devemos ser dogmáticos).” Essas figuras imaginadas eram para o poeta "tão visíveis e minhas como as coisas daquilo a que chamamos, porventura abusivamente, a vida real." Notemos o clima de incerteza que nos apresenta Pessoa, questionando a realidade e a imaginação em meio a uma sociedade cujos avanços tecnocientíficos nunca estiveram tão desenvolvidos; a crítica do sujeito se volta ao íntimo, apontando as incertezas que transcendiam o domínio da ciência moderna.

Bernardo Soares, ajudante de guarda-livros na cidade de Lisboa, é considerado um semi-heterônimo de Fernando Pessoa, assim como especifica o ortônimo no seguinte trecho da mesma carta em foco:

O meu semi-heterónimo Bernardo Soares, que aliás em muitas coisas se parece com Álvaro de Campos, aparece sempre que estou cansado ou sonolento, de sorte que tenha um pouco suspensas as qualidades de raciocínio e de inibição; aquela prosa é um constante devaneio. É um semiheterónimo porque, não sendo a personalidade a minha, é, não diferente da

2 PESSOA. Carta de 13 jan. 1935, para Adolfo Casais Monteiro. Disponível em: http://arquivopessoa.net/. Acesso em 15 jun. 2012. 
minha, mas uma simples mutilação dela. Sou eu menos o raciocínio e a afectividade. $^{3}$

Bernardo Soares é uma "mutilação" de Fernando Pessoa, um fragmento de sua personalidade, sendo, entre as criações heteronímicas, o mais próximo do ortônimo, de modo que é o único a tematizar a questão da identidade e alteridade. Isso está ligado não só a esta proximidade entre ambos, mas também aos motivos psicológicos e emocionais que possibilitam em Pessoa o estado anímico próprio do semi-heterônimo, que aparece, como mencionado, quando está cansado e sonolento, com menor capacidade de raciocínio e de inibição, possibilitando um outro grau de reflexão, um constante devaneio.

Em carta a Armando Cortes-Rodrigues, datada de 4 de outubro de 1914, encontramos: “O meu estado de espírito actual é de uma depressão profunda e calma. Estou há dias ao nível do Livro do Desassossego." " Em outra carta para o mesmo destinatário, em 19 de novembro do mesmo ano, encontramos: "O meu estado de espírito obriga-me agora a trabalhar bastante, sem querer, no Livro do desassossego. Mas tudo fragmentos, fragmentos, fragmentos." ${ }^{5}$ Nessa última colocação notamos que o semi-heterônimo está associado aos momentos de crise, sendo o seu estado de espírito fator que obriga a expressar-se em fragmentos: mutilações do todo, assim como Bernardo Soares da própria personalidade de Pessoa.

A apresentação que Fernando Pessoa faz de Bernardo Soares no prefácio do Livro do desassossego é importante para a compreensão da obra, da personagem e da áurea sociocultural na qual está circunscrita. É uma apresentação que o ortônimo faz do semi-heterônimo, num processo de veridicção constitucional da heteronímia: a tentativa do ortônimo para convencer o público de que seu semi-heterônimo não é um ente ficcional.

Pessoa comenta que costumava almoçar num pequeno restaurante em Lisboa, por "desejo de sossego e conveniência de preços", situado numa sobreloja, onde, exceto aos domingos, era frequentada por "tipos curiosos, caras sem interesse, uma série de apartes na vida." (PESSOA, 2006, p. 37). Quando jantava pelas sete horas, costumava encontrar um

3 PESSOA. Carta de 13 jan. 1935, para Adolfo Casais Monteiro. Disponível em: http://arquivopessoa.net/. Acesso em 15 jun. 2012.

4 PESSOA. Carta de 04 out. 1914, para Armando Cortes-Rodrigues. Disponível em: http://arquivopessoa.net/. Acesso em 15 jun. 2012.

5 PESSOA. Carta de 19 nov. 1914, para Armando Cortes-Rodrigues. Disponível em: http://arquivopessoa.net/. Acesso em 15 jun. 2012. 
indivíduo (a quem não nomeia ao longo do prefácio), cujo aspecto, pouco a pouco, veio a interessar-lhe: sujeito de uns trinta anos, magro, um tanto curvado quando sentado, "vestido com certo desleixo não totalmente desleixado" (PESSOA, 2006, p. 37). "Na face pálida e sem interesse de feições um ar de sofrimento não acrescentava interesse, e era difícil definir que espécie de sofrimento esse ar indicava - parecia indicar vários, privações, angústias, e aquele sofrimento que nasce da indiferença que provém de ter sofrido muito.” (PESSOA, 2006, p. 37). O primeiro traço que fez Pessoa interessar-se por Bernardo Soares foi o fato de que este "Reparava extraordinariamente para as pessoas" (PESSOA, 2006, p. 37), mas com um interesse especial, "como se interessando-se por elas sem querer fixar-lhes as feições ou detalhar-lhes as manifestações de feitio.” (PESSOA, 2006, p. 37).

Certa vez entraram no mesmo horário e começaram uma conversa casual. Pessoa, quando questionado se escrevia, fala sobre a revista "Orpheu", sendo deveras elogiado, mesmo tendo Bernardo Soares comentado que a mesma não lhe "trouxera propriamente novidade: e timidamente observou que, não tendo para onde ir nem que fazer, nem amigos que visitasse, nem interesse em ler livros, soia gastar as suas noites, no seu quarto alugado, escrevendo também.” (PESSOA, 2006, p. 38). Sobre os dois quartos do ajudante de guarda-livros, Pessoa ressalta que os teria mobiliado, a custo de coisas essenciais, com certo luxo, apontando para as confortáveis cadeiras, os reposteiros e os tapetes. "Dizia ele que assim se criara um interior 'para manter a dignidade do tédio'. No quarto à moderna o tédio torna-se desconforto, mágoa física." (PESSOA, 2006, p. 37).

Nunca teve de se defrontar com as exigências do estado ou da sociedade. Às próprias exigências dos seus instintos ele se furtou. Nada o aproximou nunca nem de amigos nem de amantes. Fui o único que, de alguma maneira, estive na intimidade dele. Mas — apesar de ter vivido sempre com uma falsa personalidade sua, e de suspeitar que nunca ele me teve realmente por amigo - percebi sempre que ele alguém havia de chamar a si para lhe deixar o livro que deixou. (PESSOA, 2006, p. 39).

Pessoa nos apresenta Bernardo Soares como um sujeito enigmático, até mesmo tendo "vivido sempre com uma falsa personalidade", com certo ar de indiferença próprio de quem muito sofreu, sem amigos, sem interesse por livros, apenas interessado em escrever o que nos é apresentado como Livro do desassossego. Assim, como um flaneur que está às margens da sociedade, observando e escrevendo suas sensações acerca do que vê, BS deixou suas 
impressões escritas em fragmentos: "Nestas impressões sem nexo, nem desejo de nexo, narro indiferentemente a minha autobiografia sem factos, a minha história sem vida. São as minhas Confissões, e se nelas nada digo, é que nada tenho que dizer.” (PESSOA, 2006, p. 50).

Pessoa salienta no prefácio a questão de seu semi-heterônimo nunca ter precisado se defrontar com as exigências do estado ou da sociedade. Vale lembrar que o livro foi escrito num período entre guerras, época bastante intensa em toda a Europa, com grande quantidade de circulação de informação e culturas distintas. Desse modo, a posição de Bernardo Soares, de apatia e alheamento perante a sociedade e a tal circulação de informações, consiste num fator crítico e reativo a tal panorama sócio-cultural.

Não me submeto ao estado nem aos homens; resisto inertemente. O estado só me pode querer para uma acção qualquer. Não agindo eu, ele nada de mim consegue. Hoje já não se mata, e ele apenas me pode incomodar; se isso acontecer, terei que blindar mais o meu espírito e viver mais longe a dentro dos meus sonhos. Mas isso não aconteceu nunca. Nunca me apoquentou o estado. Creio que a sorte soube providenciar. (PESSOA, 2006, p. 142-143).

Bernardo Soares, ajudante de guarda-livros na cidade de Lisboa, blinda seu espírito perante as exigências da sociedade e do Estado, refugiando-se dentro de seus sonhos. Aqui notamos um aspecto importante do Modernismo, em especial na literatura de Pessoa: a questão da duplicidade, que consiste na representação de duas realidades que se mesclam e se fundem, uma voltada ao real e a outra voltada à imaginação.

Notemos que na citação anterior de Bernardo Soares fala de refugiar-se em seus sonhos, de modo a blindar seu espírito contra a "realidade". No entanto, quando falamos de realidade, sobre o que falamos? Estamos num livro que, desde a sua forma, reflete a crise de identidade do sujeito moderno, uma vez que é diluída a noção de totalidade do indivíduo; do mesmo modo, traz a ideia de um livro aberto, uma série de fragmentos sem uma linearidade precisa. "A única realidade para mim são as minhas sensações. Eu sou uma sensação minha. (...) Procurar o sonho é pois procurar a verdade, visto que a única verdade para mim sou eu próprio.” (PESSOA, 2006, p. 521-522).

O sujeito refugia-se nas sensações e, sendo elas sempre individuais, levam a uma noção de ausência da verdade absoluta e à eterna sensação de incompletude. Assim, o Livro do desassossego consiste numa série de fragmentos oriundos da subjetividade de Bernardo Soares, suas impressões do real e suas as projeções oníricas. Se a única verdade são as próprias 
sensações, há uma relativização do conceito de verdade e o ser, que sempre sente algo novo, torna-se sempre um outro, um novo ser.

Viver é ser outro. Nem sentir é possível se hoje se sente como ontem se sentiu: sentir hoje o mesmo que ontem não é sentir — é lembrar hoje o que se sentiu ontem, ser hoje o cadáver vivo do que ontem foi a vida perdida. Apagar tudo do quadro de um dia para o outro, ser novo com cada nova madrugada, numa revirgindade perpétua da emoção — isto, e só isto, vale a pena ser ou ter, para ser ou ter o que imperfeitamente somos. (PESSOA, 2006, p. 124).

Conhecemos Bernardo Soares pelas suas impressões, seus devaneios que ocorrem em diferentes espaços. O ser que se renova constantemente. O que conhecemos é apenas o instante de suas impressões; estas, porém, acontecem em diferentes gradações, se mesclando com lembranças remotas.

Os espaços mais significativos em que a obra decorre polarizam-se entre o escritório (lugar onde trabalha) e o aposento de Bernardo Soares, ambos situados na Rua dos Douradores. No seguinte fragmento do Livro notamos uma relação entre vida e arte, em que os elementos espaciais assumem grande importância, englobando um potencial simbólico em relação ao eu e ao outro, uma explanação da questão da duplicidade.

\footnotetext{
Ah, compreendo! O patrão Vasques é a Vida. A Vida, monótona e necessária, mandante e desconhecida. Este homem banal representa a banalidade da Vida. Ele é tudo para mim, por fora, porque a Vida é tudo para mim por fora.

E, se o escritório da Rua dos Douradores representa para mim a vida, este meu segundo andar, onde moro, na mesma Rua dos Douradores, representa para mim a Arte. Sim, a Arte, que mora na mesma rua que a Vida, porém num lugar diferente, a Arte que alivia da vida sem aliviar de viver, que é tão monótona como a mesma vida, mas só em lugar diferente. Sim, esta Rua dos Douradores compreende para mim todo o sentido das coisas, a solução de todos os enigmas, salvo o existirem enigmas, que é o que não pode ter solução. (PESSOA, 2006, p. 49).
}

A questão da duplicidade está bastante presente neste texto: na mesma rua está localizado o escritório e seu apartamento: um simbolizando o dia, a banalidade da vida, e o outro associado à noite, simbolizando a arte, a fantasia, mas também o aprofundamento do ser ensimesmado. O sujeito busca refúgio na arte, "que alivia da vida sem aliviar de viver". A vida está relacionada à superfície das coisas, e a arte à libertação, e a relação identidade e alteridade oscila entre estes campos. A própria ideia de o quarto estar localizado no segundo andar 
confere certa superioridade da arte sobre a vida, da fantasia sobre a superficial realidade das coisas.

Em certo fragmento o ajudante de guarda-livros aponta que, imaginando-se "liberto para sempre da Rua dos Douradores, do patrão Vasques, do guarda-livros Moreira, dos empregados todos, do moço, do garoto e do gato", como se "houvessem oferecido ilhas maravilhosas por descobrir", teria pena. Há uma grande identificação por parte de BS com os outros, como se constituíssem fragmentos de uma totalidade: "tudo isso se me tornou parte de minha vida; não poderia deixar tudo isso sem chorar, sem compreender que, por mal que me parecesse, era parte de mim que ficava com eles todos, que ao separar-me deles era uma metade e semelhança da morte.” (PESSOA, 2006, p. 46).

Identidade e alteridade se misturam, de forma que a própria consciência de si se dá em relação aos outros. O sujeito já não é uma unidade, mas um todo em comunhão, que é o outro na medida em que sente o outro, na medida em que, de certa forma, objetiva a sua identidade na figura alheia.

Um aspecto interessante acerca da relação de Bernardo Soares com outras pessoas diz respeito às observações associadas a espaços externos, passeios que ele faz pela cidade como os antigos flaneurs. Comenta que um dos seus "passeios prediletos, nas manhãs em que temo a banalidade como quem teme a cadeia" é sair pela rua, lentamente, "a ouvir os farrapos de frases que os grupos de raparigas, de rapazes, e de uns com outras, deixam cair, como esmolas de ironia, na escola invisível a minha meditação aberta.” (PESSOA, 2006, p. 93). O sujeito abstrai-se de sua personalidade, se funde com os outros mediante seus sentidos e tem como fuga da banalidade o fato de entreter-se com os outros: "Outros, que passam sós ou juntos, não falam, ou falam e eu não oiço, mas as vozes todas são-me claras por uma transparência intuitiva e rota.” (PESSOA, 2006, p. 94).

A presença do outro é representada na obra através das impressões fragmentadas do escritor, que, apesar de buscar refugiar-se no seu interior, tem interesse pelas questões exteriores, pela observação de pessoas, de paisagens. Qualquer elemento exterior é motivo para uma reflexão interior, o eu se funde no outro; se a única realidade é a sensação, a percepção do outro se funde na própria personalidade. "Não tenho uma ideia de mim próprio; nem aquela que consiste em uma falta de ideia de mim próprio. Sou um nómada da consciência de mim.” (PESSOA, 2006, p. 134). Dessa forma, sem uma identidade, sendo apenas um nada em plena 
transmutação, assentado apenas na sensação do instante, a contemplação alheia serve como um modo de dar objetividade a esse sujeito abstrato.

Criei-me eco e abismo, pensando. Multipliquei-me aprofundando-me. (...) Em cada uma dessas sensações sou outro, renovo-me dolorosamente em cada impressão indefinida. Vivo de impressões que me não pertencem, perdulário de renúncias, outro no modo como sou eu. (PESSOA, 2006, p. 123-124).

O dia abrange a banalidade, a relação do eu com o outro, o ser que se faz eco e abismo (eco, como uma ressonância do externo, e abismo como forma de relação: o distanciamento do ser em relação às coisas, a sensação de permanente solidão e alheamento). O ser se renova “dolorosamente a cada impressão indefinida", impressões, essas, que não lhe pertencem. O ser está em plena constituição de si mesmo em relação ao outro, sendo que, nesse caso, o outro nos é apresentado como o "mais pequeno episódio", que faz parte do sujeito à medida em que percebe e objetiva, mesmo que de forma vaga, a sua nulidade.

Mas a ilusão não dura muito, tanto porque não dura como porque a noite vem. E a cor das flores, a sombra das árvores, o alinhamento de ruas e canteiros, tudo se esbate e encolhe. Por cima do erro e de eu estar homem abre-se de repente, como se a luz do dia fosse um pano de teatro que se escondesse para mim, o grande cenário das estrelas. E então esqueço com os olhos a plateia amorfa e aguardo os primeiros actores com um sobressalto de criança no circo.

Estou liberto e perdido.

Sinto. Esfrio febre. Sou eu. (PESSOA, 2006, p. 98).

O ser repousa à noite, passando à ilusão do dia. O sujeito, ao se aprofundar em si mesmo, quando se sente liberto e perdido durante a noite, na Rua dos Douradores, vê abrir em si o cenário das estrelas e espera os primeiros atores. A noite, para Bernardo Soares, como já apontado, tem uma relação com a arte, com a libertação da ilusão que o dia representa (as banalidade da vida). A noite permite o aprofundamento do ser em seu interior, o encontro consigo.

No entanto, este encontro consigo mesmo, em momentos em que tenta dormir, também traz à tona a questão da relação entre identidade e alteridade. Em certo fragmento do livro, BS apresenta algumas concepções sobre o dormir, o viver e o sonhar, porém encerrando sentidos para além de suas significações ordinárias. Apesar de sua extensão, tal excerto será 
exposto quase integralmente, pois engloba o movimento em que o escritor se encontra durante a noite, um desenrolar psicológico que culmina na apreciação de um casal que, até onde podemos notar, atua no seu cenário interior, em duplicidade com a realidade externa.

Nunca durmo: vivo e sonho, ou antes, sonho em vida e a dormir, que também é vida. Não há interrupção em minha consciência: sinto o que me cerca se não durmo ainda, ou se não durmo bem; entro logo a sonhar desde que deveras durmo. Assim, o que sou é um perpétuo desenrolamento de imagens, conexas ou desconexas, fingindo sempre de exteriores, umas postas entre os homens e a luz, se estou desperto, outras postas entre os fantasmas e a sem-luz que se vê, se estou dormindo. Verdadeiramente, não sei como distinguir uma coisa da outra, nem ouso afirmar se não durmo quando estou desperto, se não estou a despertar quando durmo. (...)

Sinto isto, que depois escreverei, pois que vou já sonhando as frases a dizer, quando através da noite de meio-dormir, sinto, junto com as paisagens de sonhos vagos, o ruído da chuva lá fora, a tornar-nos mais vagos ainda. São advinhas do vácuo, trémulas de abismo, e através delas se escoa, inútil, a plangência externa da chuva constante, minúcia abundante da paisagem do ouvido. Esperança? Nada. Do céu invisível desce em som a mágoa água que vento alça. Continuo dormindo.

Era, sem dúvida, nas alamedas do parque que se passou a tragédia de que resultou a vida. Eram dois e belos e desejavam ser outra coisa; o amor tardava-lhes no tédio do futuro, e a saudade do que haveria de ser vinha já sendo filha do amor que não tinham tido. Assim, ao luar dos bosques próximos, pois através deles se coava a lua, passeavam, mãos dadas, sem desejos nem esperanças, através do deserto próprio das áleas abandonadas. Eram crianças inteiramente, pois que o não eram em verdade. De álea em álea, silhuetas entre árvore e árvore, percorriam em papel recortado aquele cenário de ninguém. E assim se sumiram para o lado dos tanques, cada vez mais juntos e separados, e o ruído da vaga chuva que cessa é o dos repuxos de para onde iam. Sou o amor que eles tiveram e por isso os sei ouvir na noite em que não durmo, e também sei viver infeliz. (PESSOA, 2006, p. 323324).

No primeiro parágrafo é questionado o conceito de realidade na medida em que confessa que nunca dorme, antes sonha em vida e no sono (que também é vida). O sujeito é figurativizado como uma imagem em movimento, imagens conexas ou desconexas, "fingindo sempre de exteriores", postas entre os outros que convivem com o mesmo, quando desperto, "entre os homens e a luz", e quando dormindo, "entre os fantasmas e a sem-luz". A ideia de que está desperto ou dormindo ocorre como fusão, assim como eu e outro, realidade e ilusão o sujeito já está imerso em relativismos e na constante incerteza que o abala. 
O segundo parágrafo percorre novamente o conceito de duplicidade e, nesse meiodormir, há uma fusão entre a realidade interior e exterior, "junto com as paisagens de sonhos vagos" o som da chuva torna o sujeito ainda mais vago. A ideia do vago no interior do sujeito não deixa de transparecer o nada que o identifica, e nessa ausência de si mesmo, ainda que de forma pouco definida, através de sua sensação, a escuta da chuva, bem como as paisagens objetivam o sujeito da sua nulidade.

O terceiro parágrafo nos apresenta uma espécie de desintegração do próprio sujeito, sendo o outro de seu espetáculo interior. É narrado, repleto de paradoxos e negações, o passeio de dois jovens "através do deserto próprio das áleas abandonadas", percorrendo “em papel recortado aquele cenário de ninguém”. É como se o sujeito mesclasse ao som da chuva o passeio dos jovens, uma projeção onírica, onde os outros protagonizam o cenário interior.

O fragmento analisado encerra um movimento de despersonalização do sujeito, onde os estímulos exteriores se fundem com seus sonhos: primeiramente, um processo de despersonalização do eu, despontando uma série de palavras que bem expressam seu interior: vago, vácuo, abismo e nada. Numa segunda instância, o próprio eu se manifesta através da projeção onírica de um casal que passeia, concluindo ser, este eu, o "amor que eles tiveram".

"Meu Deus, meu Deus, a quem assisto? Quantos sou? Quem é eu? O que é este intervalo que há entre mim e mim?” (PESSOA, 2006, p. 221). Esse intervalo entre mim e mim é o centro da identidade do sujeito moderno, o nada, o vácuo, o abismo que distancia o eu de mim mesmo e o outro de mim. O sujeito não se completa, não consegue se sentir verdadeiramente próximo de ninguém, senão com as máscaras que o esconde dos outros, mas também de si mesmo - que para além de sua nulidade, reconhece em si mesmo os outros. Dentro desse complexo, o sujeito nunca alcança sua integridade, tornando-se um indivíduo sem uma identidade: “Que fiz de mim? Nada. (...) Estátua Interior sem contornos, Sonho Exterior sem ser-sonhado.” (PESSOA, 2006, p. 227).

\section{REFERÊNCIAS BIBLIOGRÁFICAS}

BENJAMIN, Walter. Charles Baudelaire: um lírico no ange do capitalismo. São Paulo: Brasiliense, 1989. 
ELIOT, Thomas Stearns. Tradition and the individual talent. 1920. Disponível em: http://www.ua.es/personal/jalvarez/PDF/Eliot_1.pdf. Acesso em: 01 jun. 2012.

FRIEDRICH, Hugo. Estrutura da Lírica Moderna. São Paulo: Duas Cidades, 1978.

PESSOA, Fernando. Arquivo Pessoa. Disponível em: http://arquivopessoa.net/. Acesso em: 15 jun. 2012.

- (Org. Richard Zenith) Livro do Desassossego: composto por Bernardo Soares, ajudante de guarda-livros na cidade de Lisboa. São Paulo: Companhia das Letras, 2006.

REIS, Carlos. O Conhecimento da Literatura: introdução aos estudos literários. Porto Alegre: EDIPUCRS, 2003.

TODOROV, Tzvetan. A conquista da América: a questão do outro. São Paulo: Martins Fontes,1988.

(vários autores) Biblos: Enciclopédia Verbo das literaturas de língua portuguesa. Lisboa: Verbo, 2001, Vol. 4.

(vários autores) Grande Enciclopédia Larousse Cultural. São Paulo: Nova Cultural, 1998.

Artigo recebido em 21 de maio de 2013

Artigo aceito em 06 de junho de 2014 